\title{
British research audit may be last of its kind
}

David Adam, London

Researchers in the United Kingdom have an added reason for Christmas cheer - more than half of them now work in university departments that are rated as "world class". These are the findings of the British government's latest Research Assessment Exercise (RAE), a major audit of university research.

The audit's results will be used by highereducation funding councils to distribute $£ 1$ billion (US $\$ 1.5$ billion) of government money each year for institutions to spend on salaries, buildings and equipment. Departments with the best grades get the lion's share of the cash, whereas poor scorers get nothing.

However, while the many departments with improved grades celebrate the outcome, some are suggesting that the exercise should be the last of its kind. Critics argue that, with around $40 \%$ of departments scoring 5 or $5^{\star}$ - the best possible grades - and with others desperately skewing their priorities to join this enlarged élite, it is time to replace the exercise with something more subtle.

"The introduction of the RAE was a good idea," says Richard Sykes, head of Imperial College in London. "It made people sit up, and it has certainly improved standards. But I think it has lived its life now. I would like to see this being the last RAE of the old style."

Since its introduction in 1986, the RAE has attracted widespread interest from other governments around the world, most of which would like to make their research universities more efficient. This year, the exercise itself cost some $\mathfrak{E} 40$ million, and used 60 separate sub-

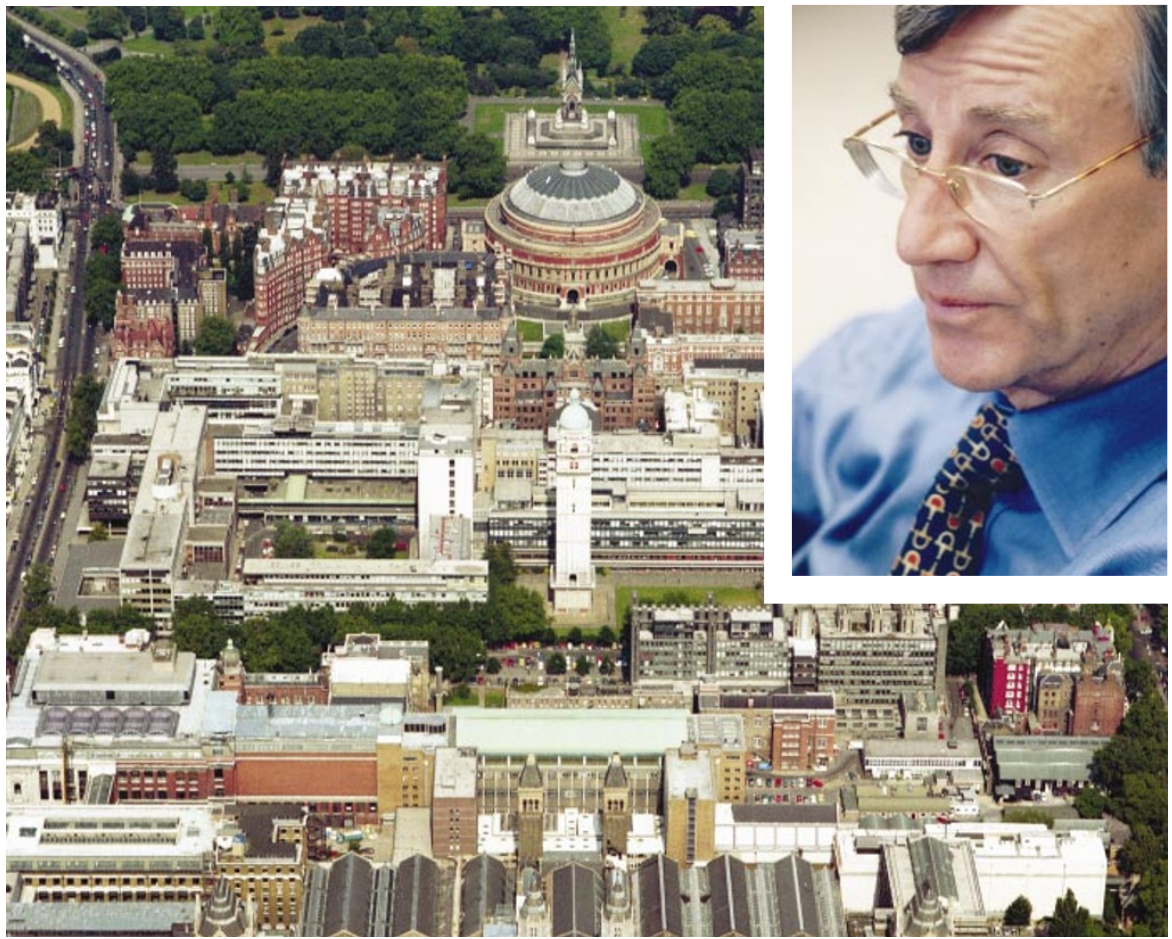

Time for a change: Imperial College's Richard Sykes says that the exercise has run its useful course.

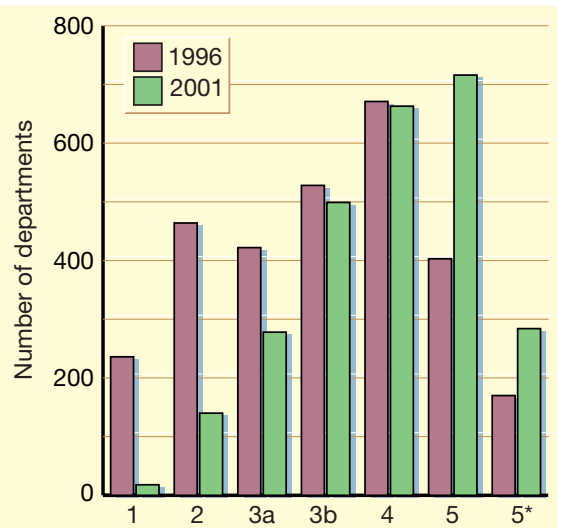

Grade inflation: department scores have surged strongly upwards since the last audit, in 1996.

ject panels to assess around 200,000 published articles from almost 50,000 researchers. The panels were asked to judge each article's level of excellence - whether national or international — using a standard scale.

This year's results, released on 14 December, showed a strong increase in the number of university departments carrying out research rated as internationally excellent: some 55\% of researchers now work in such departments, compared with $31 \%$ in 1996.

University and government officials insist that the increase in the quality of the work assessed is genuine. "The improvements in performance since the last RAE are a direct result of institutions managing their research strategically," says Howard Newby, chief executive of the Higher Education Funding Coun- cil for England (HEFCE). "Universities and colleges are to be congratulated on this outstanding performance." According to Newby, the world-class reputation of departments given top grades has been confirmed by some 300 international experts, and publication and citation counts also suggest that the quality of UK university research is improving.

In each of the five RAEs conducted since 1986 , the grades of the 1,000 or so departments surveyed have steadily improved. But there is no doubt that department heads have learned to play the system. Some, for example, have dissuaded researchers from spending time writing books, as these do not count in the RAE's reckoning. "We know the RAE has some distorting effects," says Peter Cotgreave, who heads the pressure group Save British Science.

Others point out that, by focusing on the strengths of single university departments, the exercise fails to encourage interdisciplinary research - and may even cause researchers to concentrate on singlediscipline projects that fall neatly into an established RAE subject category.

The number of departments now scoring high grades is also causing a headache for the HEFCE and the other funding councils. As the Dodo put it in Alice in Wonderland: "Everybody has won, and all must have prizes." The HEFCE has said that if the money was awarded using the same funding formula

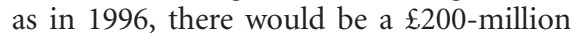
shortfall. And it has said that it will have to cap large budget increases owed to universities that have improved their standing.

Cotgreave says that the rise in the number of departments winning the best grades will make similar future tests less helpful. "The RAE has now eliminated much of its ability to discriminate," he says. "If all that will happen is that you discover that everybody is equally good, then it is pointless doing it again."

But if this RAE is the last of its type, what will replace it? "As long as we have selective funding of research we must have some kind of research assessment exercise," says John Rogers, RAE manager for the HEFCE. "But we should question whether we need to continue with this big-bang exercise every five years. Perhaps we could have a rolling programme or something with a lighter touch."

Alan Wilson, vice-chancellor of the University of Leeds and chairman of the research group of the umbrella organization Universities UK, suggests two possibilities. One would be a smaller sampling audit of departments. The second would be for the higher-education councils simply to award money in direct proportion to departments' funding from the research councils. "My personal view is that there has to be some kind of evaluation, but that it could be much simpler," Wilson says. 